\title{
Medical Image of the Week: Bronchogenic Cysts
}

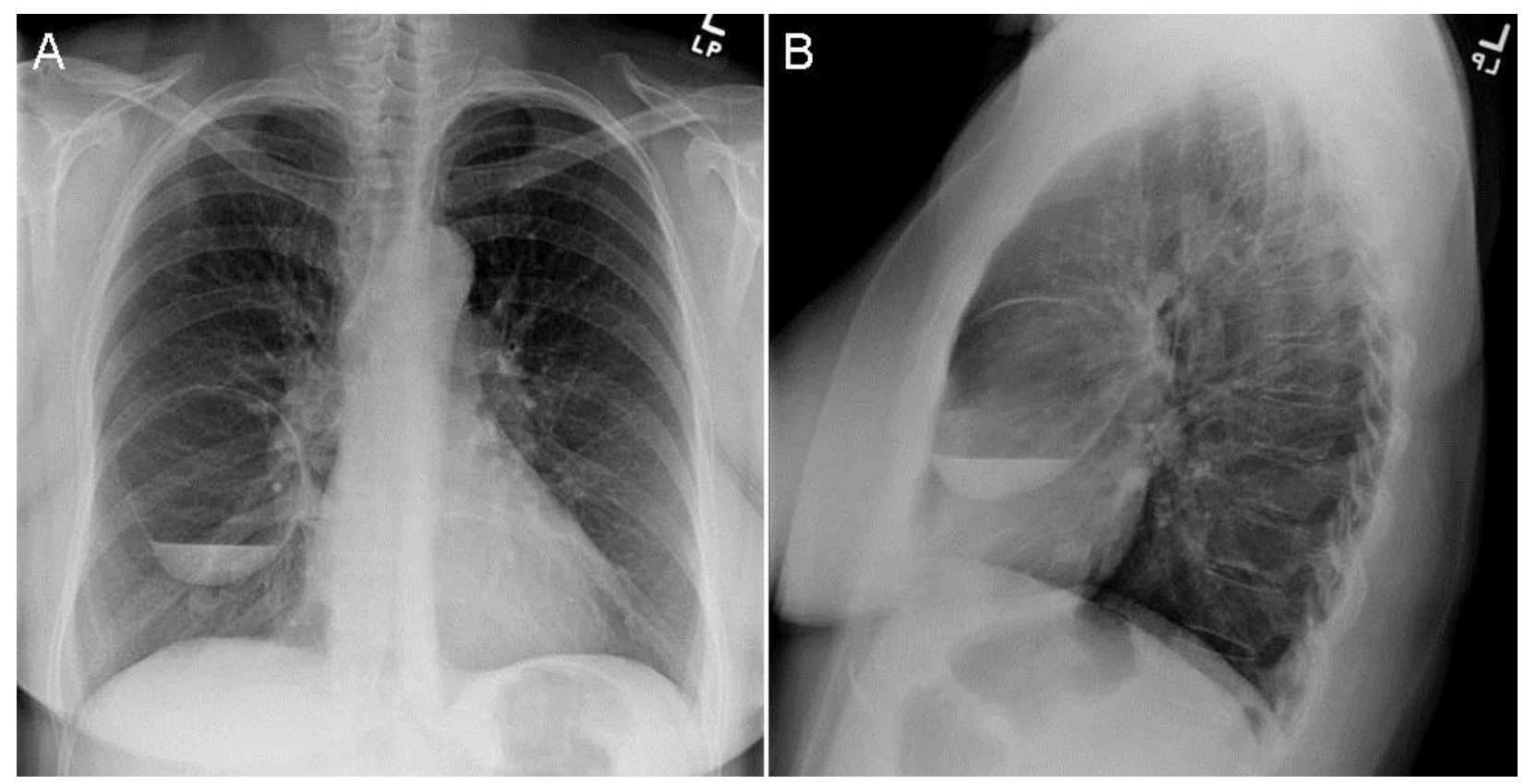

Figure 1. Posterior-anterior $(\mathrm{A})$ and lateral $(\mathrm{B})$ chest radiographs showing a large cyst with an air-fluid level in the right lung.

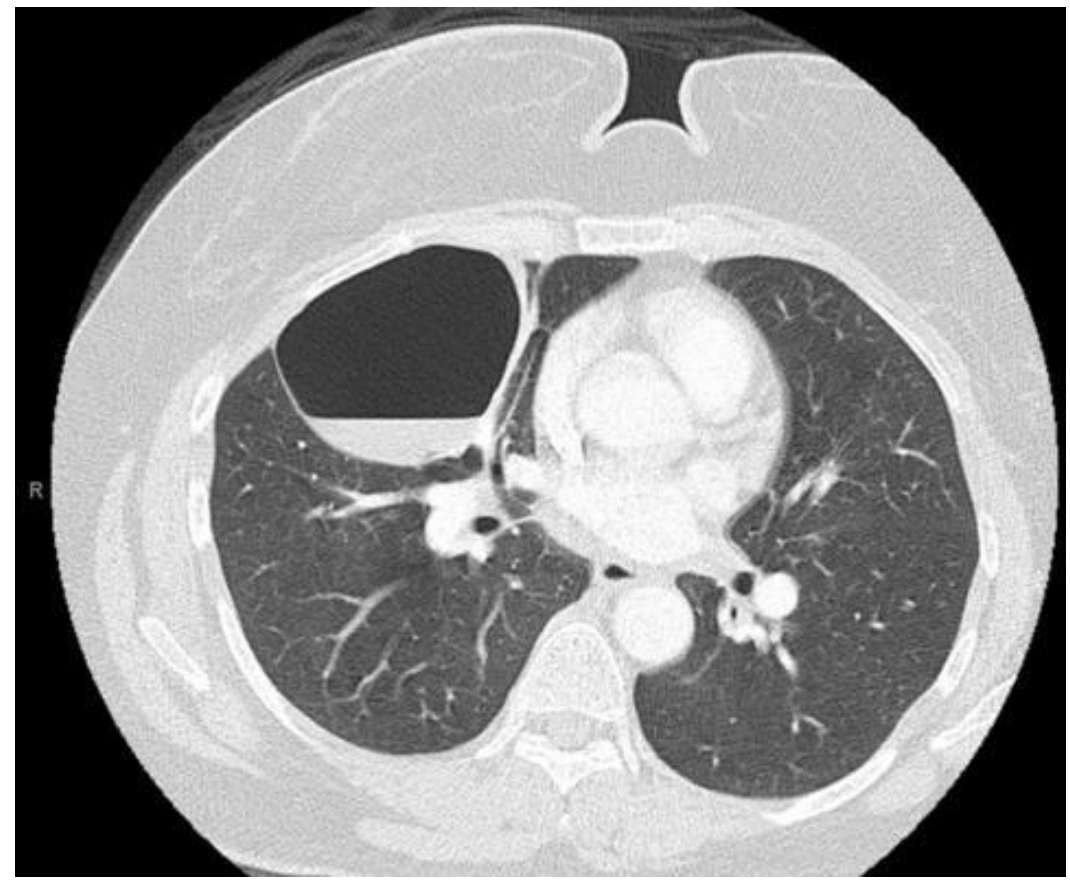

Figure 2. Representative image from thoracic CT scan in lung windows showing large right lung cyst. 
Bronchogenic cysts are congenital foregut malformations forming from abnormal budding of the bronchial tree between the $4^{\text {th }}$ and $6^{\text {th }}$ weeks of embryonic development. While identified primarily in children, the cysts are often asymptomatic and may not be identified until adulthood. Most $(70 \%)$ are within the middle mediastinum and contain fluid or proteinaceous material. When involving the parenchyma, they generally do not communicate with the tracheobronchial tree. Communication with the airways may develop following infection, procedures, or trauma and may result in lesions with an airfluid level (Figures 1 and 2). Bronchogenic cysts may be complicated by infection, bleeding, fistula formation, or most concerning, by malignant transformation. Unless the cyst contains air, it may manifest as a solitary pulmonary nodule on plain radiographs. Computed tomography or T2-weighted MRI images are used to confirm the diagnosis.

Steven P. Sears $\mathrm{DO}^{1}$ and Diana Maria Palacio $\mathrm{MD}^{2}$

${ }^{1}$ Division of Pulmonary, Allergy, Critical Care and Sleep and ${ }^{2}$ Department of Medical Imaging University of Arizona College of Medicine Tucson, AZ USA

\section{References}

1. McAdams HP, Kirejczyk WM, Rosado-de-Christenson ML, et al. Bronchogenic cyst: Imaging features with clinical and histopathologic correlation. Radiology. 2000 Nov;217(2):441-6. [CrossRef] [PubMed]

2. St-Georges R. Deslauriers J, Duranceau A, et al. Clinical spectrum of bronchogenic cysts of the mediastinum and lung in the adult. Ann Thorac Surg. 1991;52:6-13. [CrossRef] [PubMed]

3. Cardinale L, Ardissone F, Cataldi A, et al. Bronchogenic cysts in the adult: Diagnostic criteria derived from the correct use of standard radiography and computed tomography. Radiol Med. 2008;113(3): 385-94. [CrossRef] [PubMed] 